\title{
Improving Performance of Routing Protocols Using MRP Framework
}

\author{
Sohail Abid ${ }^{1,}$ Shahab Khan ${ }^{2}$ \\ ${ }^{1}$ Department of Engineering and Management Foundation University, Pakistan. \\ ${ }^{2}$ Department of Computing and Technology IQRA University Islamabad Campus Pakistan.
}

\begin{abstract}
These days MANET (Mobile Ad-hoc Network) is an amazing remarkably altering or rising technology, for the reason that of its elite nature of scattered mobile devices and self-motivated network topology. The mobile ad-hoc routing protocol follows several principles in wireless MANET's. The up to date and novel applications based on wireless technology are being produced in the private as well as commercial sectors. A lot of challenges which are facing wireless MANETs like network stability, security, energy efficiency and performance analysis etc. At present wireless ad-hoc network get much more attention because of its accessibility everywhere. As a result researchers produce several routing protocols. In this paper first of all we analyzed the performance investigation of wireless routing protocols on the basis of ROH (Routing Overhead), throughput, end-2-end delay and PDR (Packet Delivery Ratio). After that we proposed an MRP (Mixed Routing Protocol) framework which improve performance.
\end{abstract}

\section{KEYWORDS}

Study of Routing Protoco;. MANET's Routing Protocol; Proactive and Reactive Routing; MRP framework.

\section{INTRODUCTION}

Now a day mobile ad-hoc protocol acting an essential part in a wireless atmosphere. Today mobile network has become a primary element of recent communication infrastructure for its applications in mobile and personal communications. The strength of mobile ad-hoc technology is that the mobile devices can be used anywhere and at any time. In mobile ad-hoc network, all devices work as a router or end node, which participate an significant function during safeguarding and searching of routes. The breakdown of a mobile device can critically modify the performance of an ad - hoc network.

MANET is a collection of wireless devices that set up the relationship between wireless nodes exclusive of centralized management and infrastructure [1]. The wireless nodes are proficient of shifting their location and connect each other randomly in a wireless network. The whole procedure replicates, during finding the whole route, the destination mobile device sends route reply message to the source mobile device for successful route making and searching procedure [2]. The arrangement of route detection and preservation is the important process functioning in DSR [3]. The proactive routing protocol Bellman-Ford method working in DSDV[4]. The protection and marking of routes ought to be finished below some limitations for example utilization of bandwidth and minimum quantity of overhead [5]. The main goal of a routing protocol is to set up a accurate and competent route linking two mobile nodes that can be sent or received in time. 
International Journal of Ambient Systems and Applications (IJASA) Vol.2, No.1, March 2014

\section{i.PerformanCe Metric}

The performance metric of routing protocols is described as below.

\section{A. ROH (Routing Overhead)}

$\mathrm{ROH}$ is defined as the total number of routing packets during communication in a simulation.

$R=$ No of RTR.

Where "No. of RTR" represents to total number of routing packets and "R" represents Routing Overhead.

\section{B. PDF (Packet Delivery Function )}

PDF is defined as the total number of sending packets dividing by the total number of received packets.

P $=$ Pkt_S / Pkt_R

Where "Pkt_S" represent send packet and "Pkt_R" represent receive packet and "P" represent packet delivery function.

\section{Average End 2 End Delay (Average E-2-E Delay)}

During communication there are various issues that cause delay like retransmission, queuing, buffering during routes detection and latency. Minimum delay means good performance.

$$
\text { E2E Delay }=\frac{1}{m} \sum_{a=1}^{m}(R a-S a)
$$

$\mathrm{a}=\{1,2, \ldots ., \mathrm{m}\}$

$R a=$ time "a" when packet was received by destination

$\mathrm{Sa}=$ time "a" when packet was send by source

$\mathrm{m}=$ number of receiving packets.

\section{II.PREVIOUS WORK}

Birdar and his group menmers offered in his paper a performance analysis for DSR and AODV using speed as a variable parameter in NS2 [6]. Another performance analysis for DSR and AODV in NS2 using number of sources, speed and pause time as a variable parameter by G. Jayakumar and his group members [7]. Yogesh and his team presented a comparison analysis for DSR and AODV using variable parameters as the number of nodes, speed and pause time in GLOMOSIM [8]. Shaily and his team members compare ZRP, DSR and AODV using pause time as a variable parameter in QualNet [9]. Vijayalaskhmi and his group analyze performance of AODV and DSDV in his paper using pause time as variable parametert in NS2 [10]. Amr M. Hassan and his team select DSDV and DSR and evaluate the performance on the basis of Routing Overhead (ROH), Packet Delivery Latency and Packet Delivery Function (PDF) versus node density [11]. The comparative study of DSDV, AODV and DSR on the basis of "ROH", "Packet 
International Journal of Ambient Systems and Applications (IJASA) Vol.2, No.1, March 2014

Dropped Ratio" and "Packet Delay" by Kaushik et al. [12]. In [13], W.R. S. Jeyaseelan and Sh. Hariharanthe evaluate performance of DSR, OLSR and AODV. Under high mobility Shah and his group members simulate AODV, DSDV and DSR in NS-2 [14]. A Behavioral Study of Routing Protocols like AODV, DSDV and DSR in ns2 by Kumar Sharma and his group [15]. Maashri and his group members perform another comparative study of routing protocols at high mobility [16]. Kumari et al. also investigate performance analysis of OLSR, AODV and DSDV in Freeway mobility model [17].

\section{if Proposed Frame Work And Results}

I propose a new routing protocol framework MRP (Mixed Routing Protocol) on the basis of my results. The framework is as under:

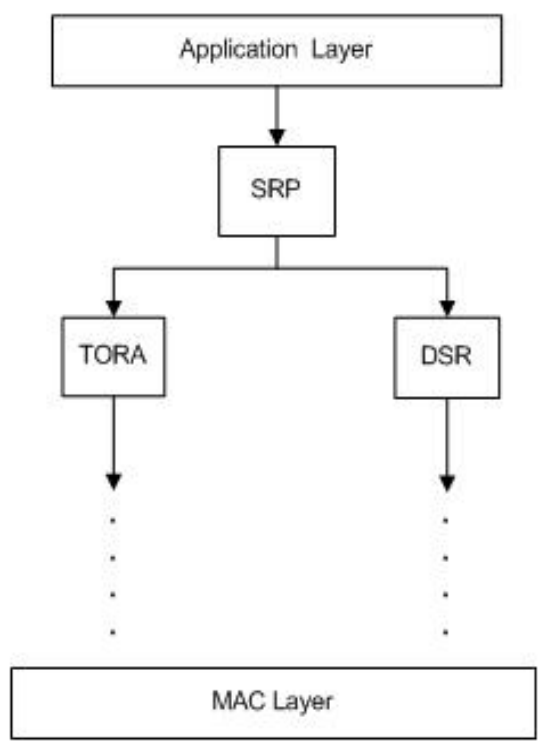

Figure 1a: Proposed MRP

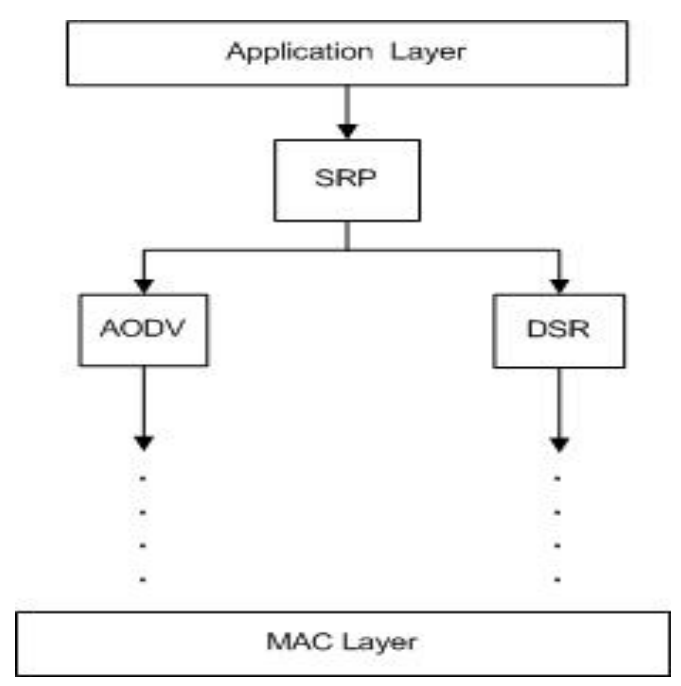

Figure 1b: Proposed MRP 
International Journal of Ambient Systems and Applications (IJASA) Vol.2, No.1, March 2014

In the framework SRP stands for swap routing protocol. In our proposed framework I select two best routing protocols on the basis of our simulation and SRP switch routing protocols during communication. This method work in application layer. First of all I take two protocols AODV and DSR and simulate in ns2 and compare with other routing protocols. Secondly I change the combination of routing protocols, this time I take Tora and DSR. Simulate in NS2 and compare with other routing protocols. Our MRP framework performs better than other routing protocols.

In other words performance of my proposed framework increased, my new results are as under.

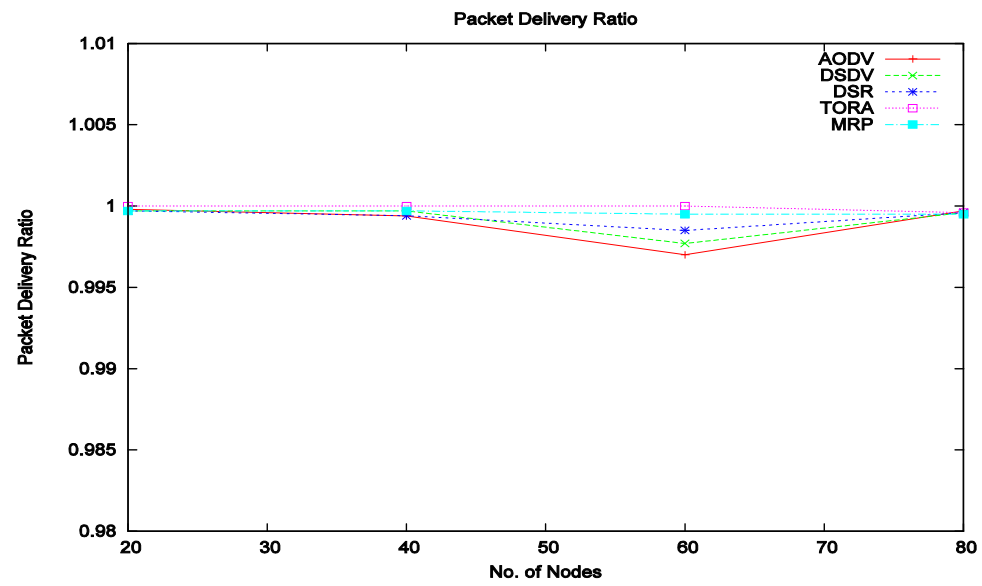

Figure 2: PDF

In the above figure 2 , it is clear that our proposed frame gives performance nearly equal to TORA. In other words MRP gives best performance in PDF.

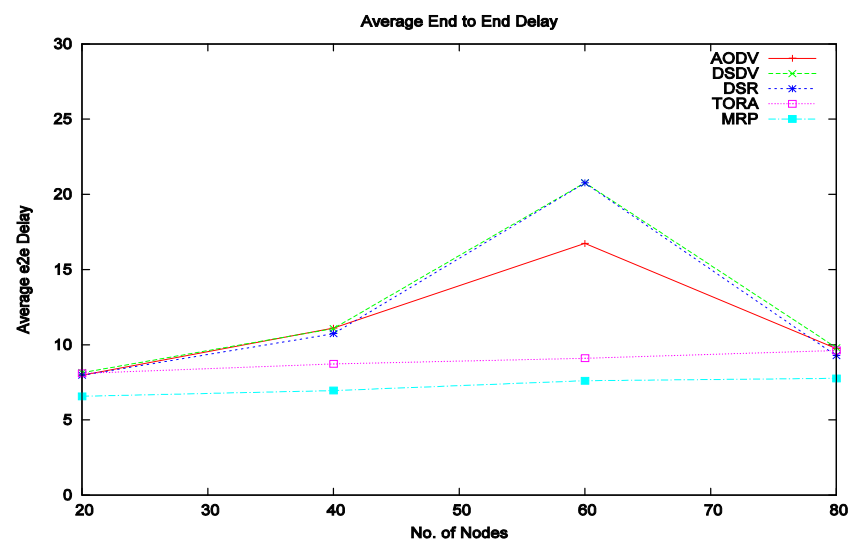

Figure 3: Avg. E2E Delay

In the above figure 3, it is clear that our proposed frame gives performance better than TORA. In other words MRP gives best performance in e2e delay. 
International Journal of Ambient Systems and Applications (IJASA) Vol.2, No.1, March 2014

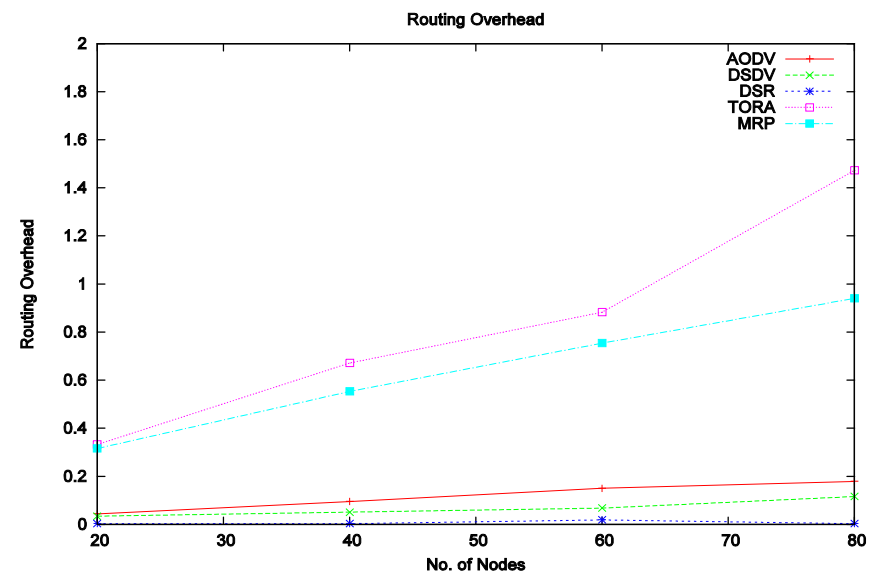

Figure 4: RO

In the above figure 4, it is clear that our proposed frame gives performance nearly equal to DSR. In other words MRP gives best performance in $\mathrm{ROH}$.

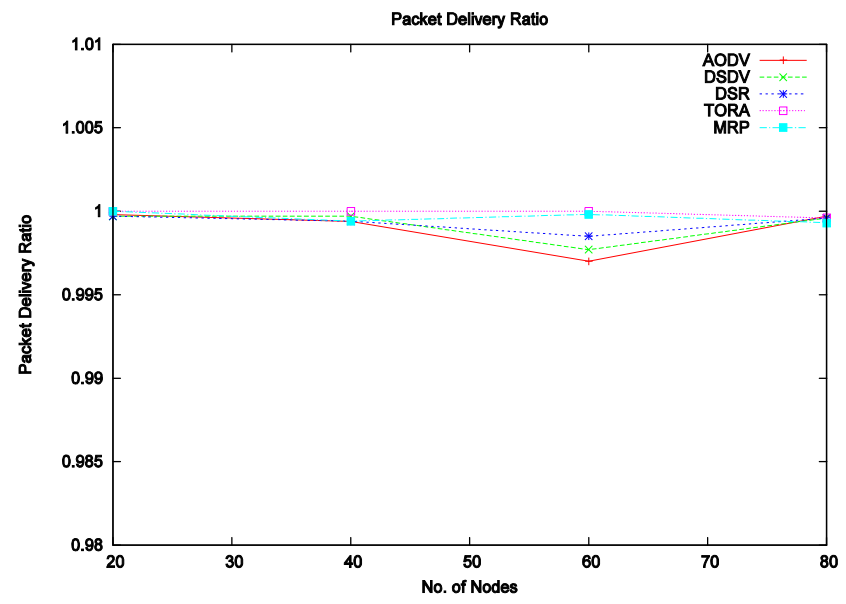

Figure 5: PDF

In the above figure 5, it is clear that our proposed frame gives performance nearly equal to TORA. In other words MRP gives best performance in PDF. 


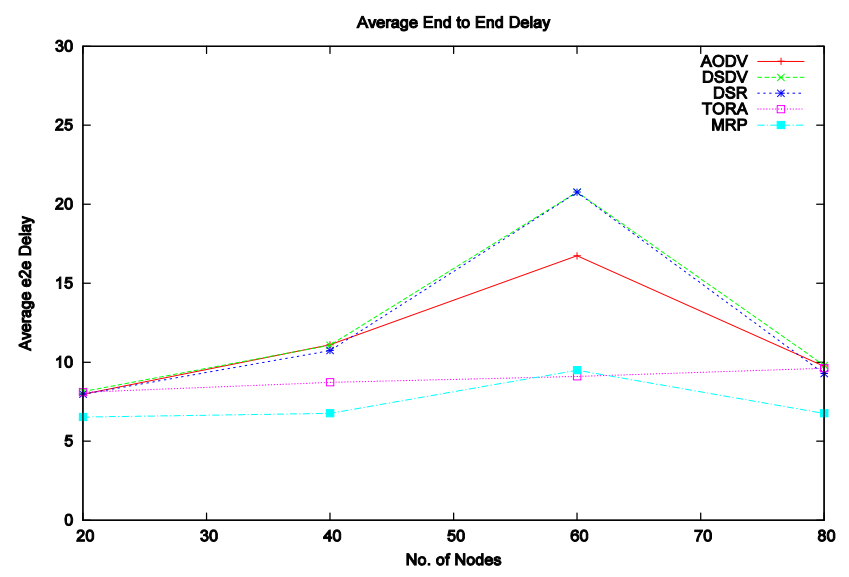

Figure 6: Avg. E2E Delay

In the above figure 6 , it is clear that our proposed frame gives performance better than TORA. In other words MRP gives best performance in e2e delay.

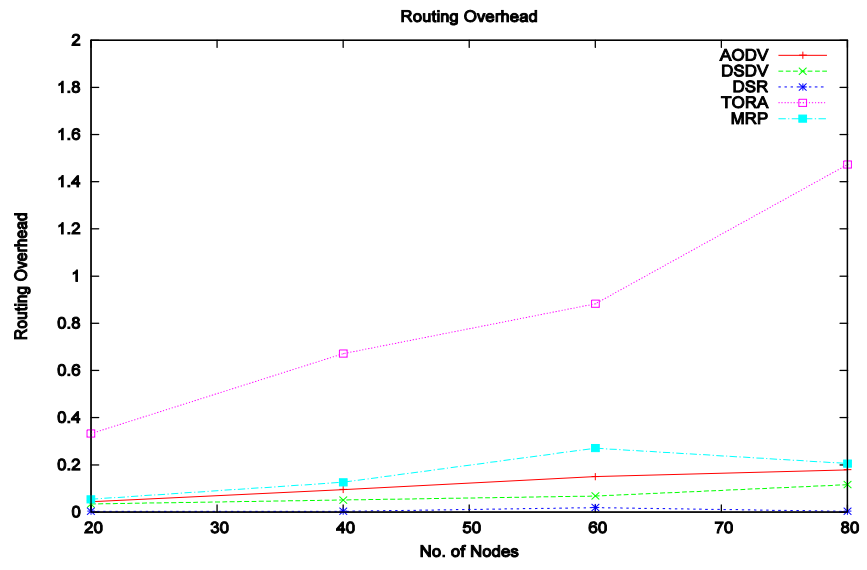

Figure 7: RO

In the above figure 7, it is clear that our proposed frame gives performance nearly equal to DSR. In other words MRP gives best performance in $\mathrm{ROH}$.

\section{Conclusion}

This research paper I give a summary of Wireless Ad-hoc network and talk about that how these types of networks requires performance as most essential constraints. A comprehensive study of the performance analysis strategies and performance analysis metrics is provided. According to this study it is focusing on four performance analysis methods to achieve better performance. I evaluate and simulate four routing protocols with my proposed MRP framework to investigate the performance analysis of routing protocols. On the basis of my simulation results it is clear that my proposed framework to increase performance of routing protocols. The idea of this research work is to develop an efficient performance routing protocol and allows researchers to select the well define routing method. 
International Journal of Ambient Systems and Applications (IJASA) Vol.2, No.1, March 2014

\section{REFERENCES}

[1] Pierpaolo Bergamo and Alessandra etl.," Distributed Power Control for Energy Efficient Routing in Ad Hoc Networks ", Wireless Networks 10, 29-42, 2004, Kluwer Academic Publishers, Manufactured in The Netherlands.

[2] N.Pantazis, S. Nikolidakis and D. Vergados, "Energy Efficient Routing Protocols in Wireless Sensor Networks for Health Communication Systems", Ublished in PETRA, pp. 9-13, ACM ISBN: 978-160558-409-6, in 2009.

[3] L.Chakers and El. Belding, "AODV Routing Protocol Implementation Design”, Published in 24th International Conference ICDCSW in 2004.

[4] S.A. and P. Tijare, "Performance Comparison of AODV, DSDV, OLSR and DSR Routing Protocols in Mobile Ad Hoc Networks", International journal of information technology and knowledge management, Vol. 2, issue 2, page 545-548, in Dec 2010.

[5] GuntupalliLakshmikanthMr Gaiwak and P. Vyavahare, "Simulation Based Comparative Performance Analysis of Ad-hoc Routing Protocols", INSPEC, ISBN: 978-1-4244-2408-5, page. 1-5, published in 2008.

[6] S.R.Birdar, H.Sarma, K. Sharma, S. Kumar Sarkar, Puttamadappa C, "Performance Comparison of Reactive Routing Protocols of MANETs using Group Mobility Model”, International Conference on Signal Processing Systems in 2009.

[7] G.Jayakumar and G. Gopinath, "Performance comparison of two on-demand routing protocols for adhoc networks based on random way point mobility model," Published in American Journal of Applied Sciences, volume 5, issue no. 6, page no. 649-664, June 2008.

[8] Y.Chaba, Y. Singh and M. Joon, "Simulation Based Performance Analysis of On-Demand Routing Protocols in MANETs," Published in Second International Conference on Computer Modeling and Simulation in 2010.

[9] S.Mittal and P. Kaur, "Performance Comparison of AODV, DSR and ZRP Routing Protocols in MANET's", Published in International Conference on Advances in Computing, Control and Telecommunication Technologies in 2009.

[10] Vijayalaskhmi M. Avinash Patel, Linganagouda, "QoS Parameter Analysis on AODV and DSDV Protocols in a Wireless Network", International Journal of Communication Network and Security, Vol-1, Issue-1, published in 2011.

[11] Amr M. Hassan, Mohamed I. Youseef, Mohamed M.Zahra, "Evaluation of Ad Hoc Routing Protocols in Real Simulation Environemts", Computer Engineering and Systems (IEEE), ISBN: 1-4244-0271-9, INSPEC Accession Number: 9232342, On page(s): 288 - 293, in 2006.

[12] S.Kaushik, P.R.Deshmukh, "Comparision of effectiveness of AODV, DSDV AND DSR routing protocols in mobile ad hoc networks", International Journal of Information Technology and Knowledge Management July-December 2009, Volume 2, No. 2, pp. 499-502.

[13] W.R. S. Jeyaseelan and Sh. Hariharan, "Investigation on routing protocols in MANET", International Journal of Research and Reviews in Information Sciences (IJRRIS), Vol. 1, No. 2, June 2011,ISSN: 2046-6439.

[14] S. Shah, A. Khandre, M. Shirole and G. Bhole, "Performance evaluation of sd hoc routing protocols using NS2 simulation", National Conference on Mobile and Pervasive Computing (CoMPC-2008).

[15] A.Kumar Sharman and N. Bhatia, "Behavioral study of MANET routing protocols by using NS-2", IJCEM International Journal of Computational Engineering \& Management, Vol. 12, April 2011 ISSN (Online): 2230-7893.

[16] A.Al-Maashri, M. Ould-Khaoua, "Performance analysis of MANET routing protocols in the presence of self-similar traffic", In Proceedings of the 31st IEEE Conference on Local Computer Networks, 2006, 14-16 November 2006, pages pp. 801-807, Tampa, Florida, USA.

[17] S.Kumari, S. Maakar, S. Kumar and R. K. Rathy, "Traffic pattern based performance comparison of AODV, DSDV \& OLSR MANET routing protocols using freeway mobility model”, International Journal of Computer Science and Information Technologies, Vol. 2 (4), 2011, 1606-1611. 
International Journal of Ambient Systems and Applications (IJASA) Vol.2, No.1, March 2014

\section{Authors}

Sohail Abid: (Mobile No: +92-321-5248497)

Sohail Abid MS in Telecomm and Network and working as System Administrator at Foundation University Rawalpindi Campus.

Shahab Khan: (Mobile No: +92-301-8531492)

Shahab Khan Student of MS (TN) at IQRA University Islamabad. 